\title{
Sensitivity analysis overlaps of friction elements in cartridge seals
}

\author{
Milan Žmindák ${ }^{1, *}$, Miloš Falat ${ }^{2}$ \\ ${ }^{1}$ Faculty of Mechanical Engineering, Department of Applied Mechanics, University of Žilina, \\ Univerzitná 1, 01026 Žilina, Slovak Republic \\ ${ }^{2}$ Schaeffler Slovakia, s.r.o, Ul. Dr. G. Schaefflera 1, 02401 Kysucké Nové Mesto, Slovak Republic
}

\begin{abstract}
Cartridge seals are self-contained units consisting of a shaft sleeve, seals, and gland plate. The applications of mechanical seals are numerous. The most common example of application is in bearing production for automobile industry. This paper deals with the sensitivity analysis of overlaps friction elements in cartridge seal and their influence on the friction torque sealing and compressive force. Furthermore, it describes materials for the manufacture of sealings, approaches usually used to solution of hyperelastic materials by FEM and short introduction into the topic wheel bearings. The practical part contains one of the approach for measurement friction torque, which results were used to specifying the methodology and precision of FEM calculation realized by software ANSYS WORKBENCH. This part also contains the sensitivity analysis of overlaps friction elements.
\end{abstract}

Keywords: sensitivity analysis, sealing, hyperelasticity, elastomer, friction torque

\section{Introduction}

Engineering modeling and simulations plays a role in designing the cars components [1]. Today engineers apply simulation tools and methods in the design phases of product development, replacing costly physical prototyping and testing with advanced numerical analyses. Mechanical face seals are used for sealing fluid at places were a rotating shafts enters an enclosure. The primary function of seals is to prevent the leakage of gaseous and liquid substances between the contact surfaces of the construction. They prevent lubricant from escaping and also protect the internal structure from the ingress of dirt. Well-sealed joint has a crucial impact on the performance and reliability of the construction. It also prevents the leakage of chemical substances from construction into the surrounding environment [2]. The degree of sealing refers to the flow of lubricant through the sealed joint per time unit.

Currently there are a lot of seals variations for wheel car bearings. Fig. 1 illustrates the development of mass-produced sealing systems in SKF [3] over the time. This diversity is historically determined by the development of increasing requirements imposed on the sealing systems as well as increasing experience of the development departments with the operation of the individual variants in practice.

\footnotetext{
* Corresponding author: milan.zmindak@,fstroj.uniza.sk

Reviewers: Juraj Gerlici, Ján Vavro
} 
Back in the 60's so-called "onelip" flat gaskets were used (Fig.1, the first left). It consists of a metal part that functions as a reinforcement for the rubber part. This part includes a flexibly deformable lip (friction element) that permanently touches the bearing ring. Its role is to prevent the permeation of impurities from the external environment to the internal construction of the bearing as well as the leakage of the lubricant.

Given the increasing demands on the sealing performance, the construction of the seal has been supplemented with another friction element (Fig. 1, second from the left) whose role was to catch those impurities that might possibly get through the first friction element. Progress was made in the 1970 s when a flinger ring was introduced to be used as presealing for the flat gasket. Unlike the flat gasket, it is attached to the internal ring of the bearing. Thanks to this, the contaminated water can easily flow out under the seallings lip.

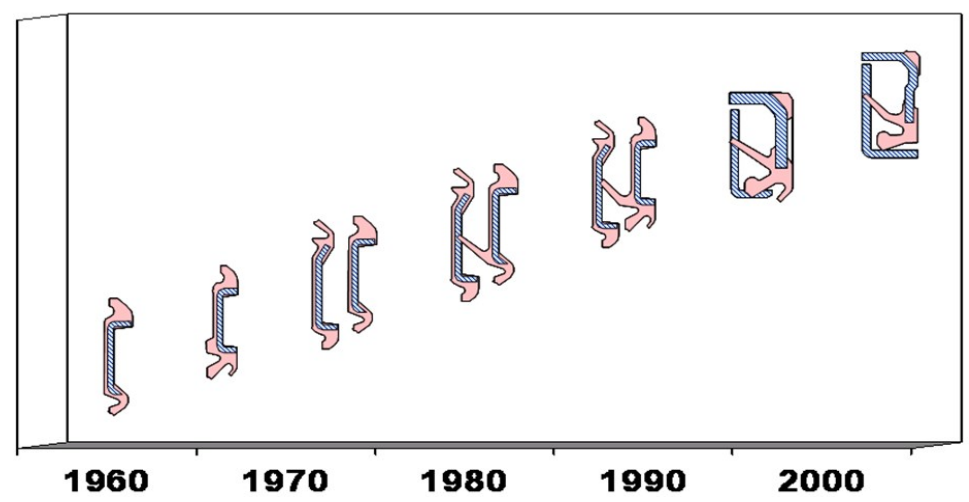

Fig. 1. Historical development of shaft seal designs used for wheel bearings

In the next decade, the concept of the flat gasket has been added with an axial friction element ( Fig. 1, third from the left). Thanks to this, the gasket could function longer before the bearing got contaminated. The space created for the lubricant reduced the deterioration of sealing friction elements of the gasket; having at the same time tightened the impact of fine surface defects. Other customer requirements, such as the inclinability of the bearing for some applications, could no more be ensured through flat gaskets. Therefore, a cassette seal (Fig.2) was developed, consisting of two assembled parts.
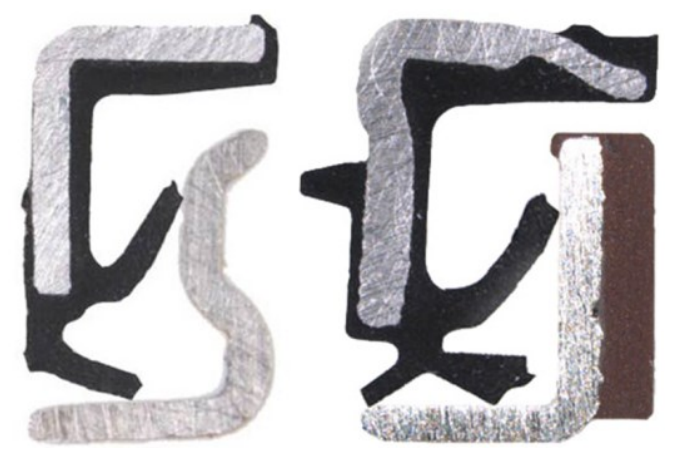

Fig. 2. Cutting through sealing gaskets. Left is cassette seal with two sealing lips, right is cassette seal with three lips and the Anti-lock Braking System (ABS) ring 
One part consists of a molded sheetmetal with vulcanized sealing friction elements, while the other consists of a sheetmetal or, alternatively, of a sheetmetal with vulcanized ABS ring (Fig.2, right). The friction elements in the first part mostly move around the second part, and not around the ground ring of the bearing. Its advantage is a better quality of the touching surfaces for the friction elements [4] as well as a higher accuracy. The main difference lies in the fact that the seal's surfaces touching both the external and internal rings are flat. This did away with the inaccuracy that was a result of the compression pressing of flat gaskets into recess. Although this process is financially more demanding, it provides a better sealing performance compared to its predecessor as well as a simpler integrability of the ABS signal generator. In 2000, the demands on the price started increasing in addition to the tightness requirements. The original design of the cassette seal was modified by removing one radial friction element.

The main aim of this article is to apply an finite element method (FEM) in the process of the designing of sealing system with respect to the decrease of the friction torque in a bearing joint. The goal is to create a simple tool to calculate the final friction torque for the sealing system of the first-generation wheel bearing (Fig.3) using the commercial software ANSYS WORKBENCH. By way of an experiment we will verify the total friction torque of the first-generation bearing and identify the friction torque of the individual components of this bearing. This experiment will include the verification of the friction torque of the partial friction torques of the seal. Using the modified seals, we will next analyse the course of the friction torques of its friction elements. For the experiment, we will use the same seals with a different friction element removed in each of them. Finally, we will analyse the impact of the overhang of the friction elements of the sealing system on the magnitude of the contact force with respect to the change of the dimensions of the sealing elements in the admissible tolerance zone.
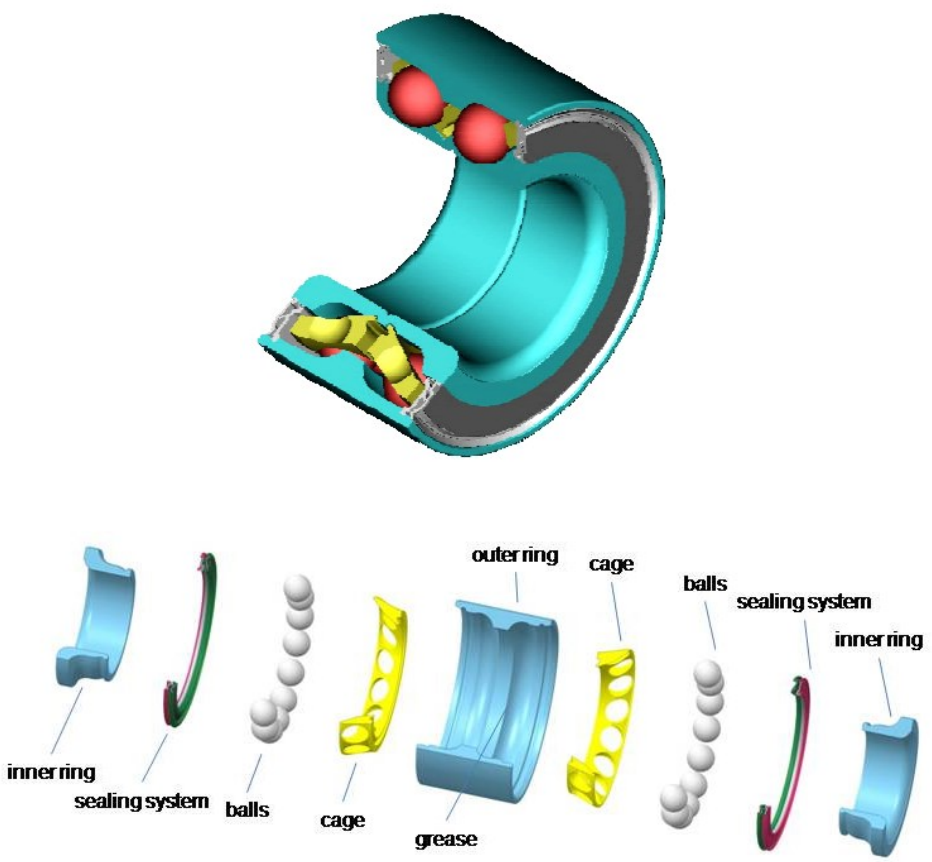

Fig. 3. First-generation wheel bearing and its components 


\section{Finite element model}

The geometrical model of the seal was created in the Creo 2 program and imported into the ANSYS Workbench program. Fig. 4 depicts a cross-section of the bearing; Fig. 5 depicts its basic parts. The final elementary model was created in the ANSYS Workbench software. The task was pursued as a linear static with $2 \mathrm{D}$-axially symmetrical final elements.

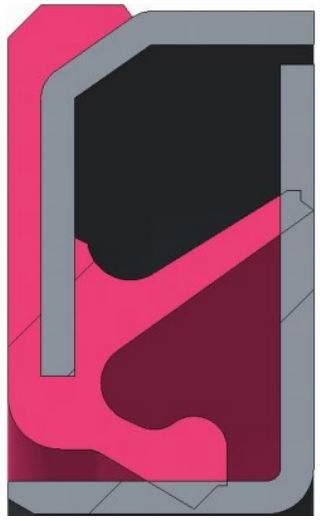

Fig. 4. Cutting through sealing

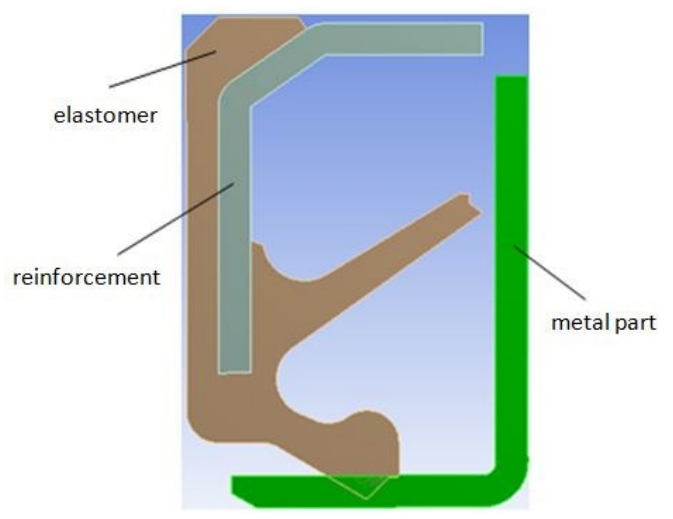

Fig. 5. 2D Seal model with the names of its components

The metal part was constructed from regular construction steel with the stress modulus of $\mathrm{E}=2.1 \mathrm{e} 05 \mathrm{MPa}$ and Poisson's ratio of $v=0.3$. The material model for the rubber part of the seal is the first-order parametric Ogden model [5] with the material constants of $\mathrm{MU} 1=2.34 \mathrm{MPa}, \mathrm{A} 1=2$ and $\mathrm{D} 1=0$. Having created the geometrical model and defined the material properties, we specified the boundary conditions. Since this is an axially symmetrical task, it is necessary to take into consideration the impact of forces effective around the whole circumference. Next, the contact conditions among the individual parts of the model are defined (Fig.6). A perfect connection between the reinforcement and the rubber is envisioned (Fig.7). A contact is defined between the rubber and the sheetmetal in both the axial and the radial directions. In comparison to its original position, the sheetmetal has been shifted by $0.7 \mathrm{~mm}$. The cover sheetmetal will be inserted to its original place during the calculation. It is therefore necessary to set up the actual contact conditions for the contact between the friction element and the cover sheetmetal so that the friction element is in the correct position. In both the axial and radial contact points we consider the friction between the rotating sheetmetal and the stationary rubber part. For the simulation purposes, we set up the detection of the contact surfaces by using the "Pinball Region" function [6]. To create an FEM web, an automatic generator of quadrangular elements is used (Fig.9).

\section{Numerical results}

The FEM analysis is divided into two separate analyses. In the first analysis, we calculate the friction torque of the axial sealing element (Fig. 10), while in the second part of the analysis and the friction torque of the radial sealing element (Fig.11). The FEM analysis was done for two time steps with the growth figure of 1 second. In the first step, the contact is identified between the radial friction element and the cover sheetmetal with the actual position of the radial friction element. In the second step, the cover sheetmetal is inserted by $0.7 \mathrm{~mm}$ into the original position so that the axial friction element gets into the correct 
position in the seal. Finally, we will calculate the reactions because the axial friction element moves in the direction of the X-axis so that it has an impact on the value of the radius $r$.

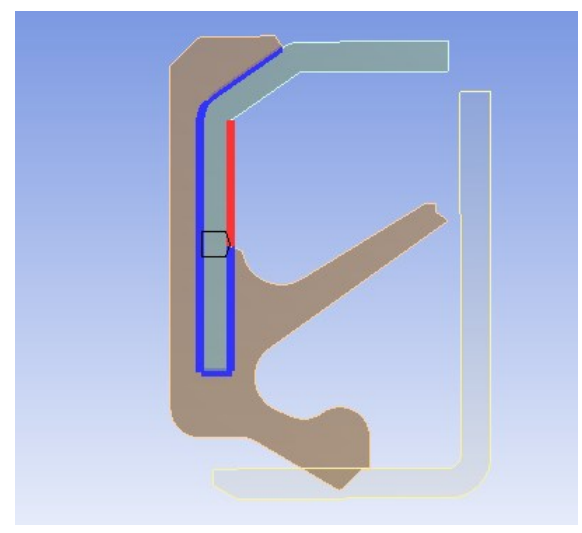

Fig. 6. Contact definition between rubber and reinforcement

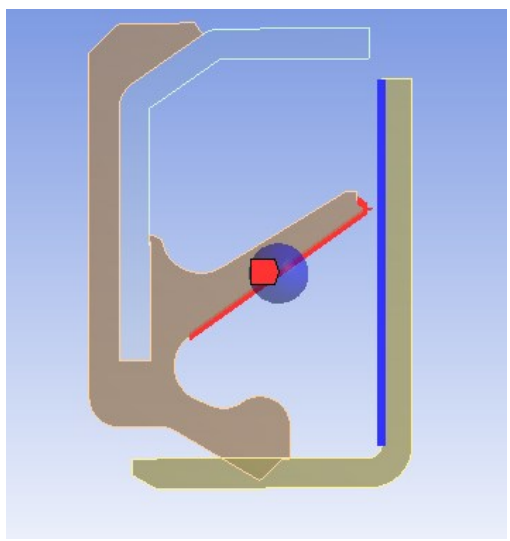

Fig. 8. Contact definition between rubber and metal part in axial direction

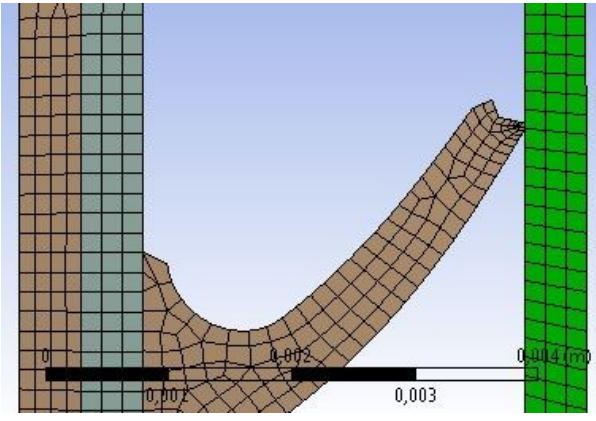

Fig. 10. Shape of axial friction element in assambled shape

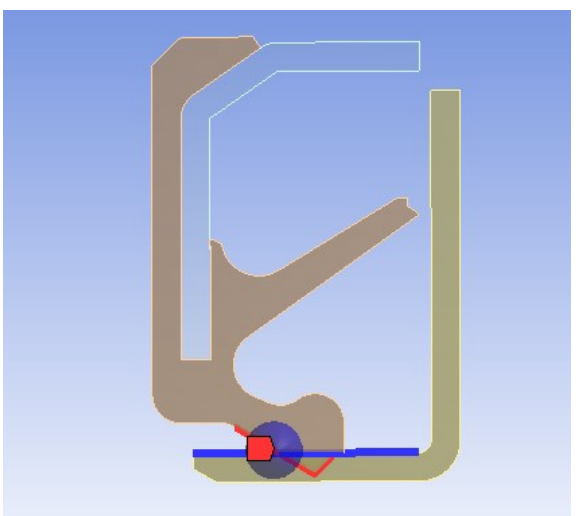

Fig. 7. Contact definition between rubber and metal part in radial direction

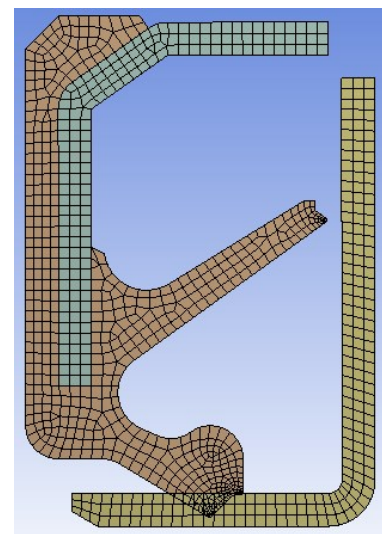

Fig. 9. Finite element mesh

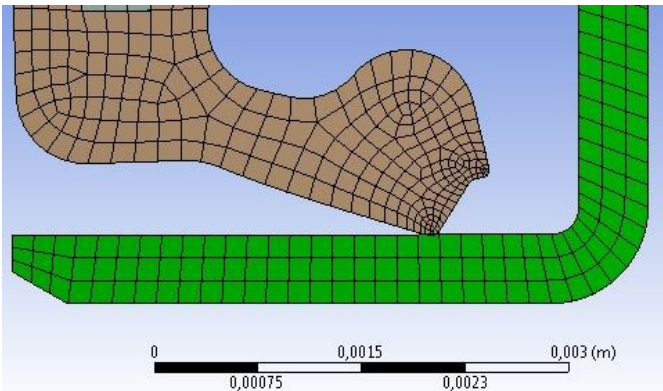

Fig. 11. Shape of radial friction element in assembled form 

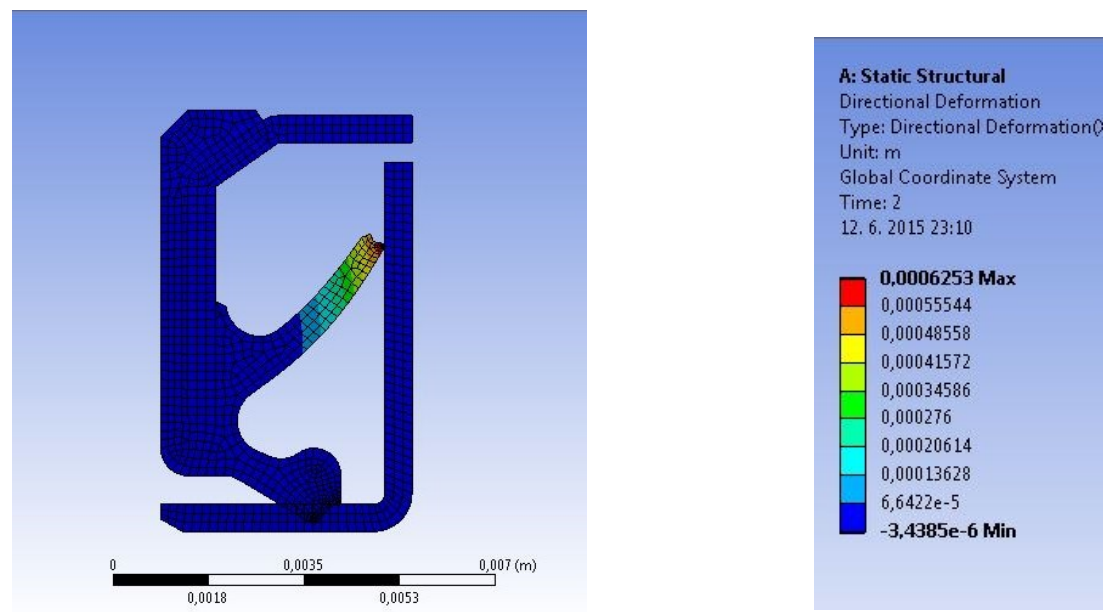

Fig. 12. Axial displacement of the friction element in an assembled and unassembled state

The calculated value of the shift of the end of the axial friction element (no-load condition) is depicted by Fig.12. It means that the change in the contact diameter of the friction element is $0.62 \mathrm{~mm}$ and it corresponds to the radius. Therefore, we can conclude that the seal touches down on the diameter of $\varnothing 61.24 \mathrm{~mm}$, whereas the value on the drawing in a no-load condition is $\varnothing 60 \mathrm{~mm}$. A reaction in the direction of the Y-axis (Fig. 13) has an impact on the other part of the seal and the direct effect has the magnitude of the friction torque.

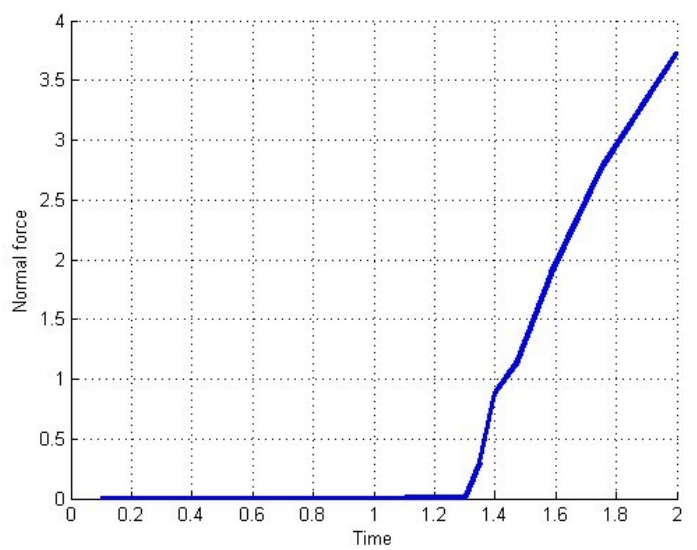

Fig. 13. Axial friction element compression force values in the axial direction in each calculation step

The value of the final compressive force of the axial friction element is $3.73 \mathrm{~N}$, and therefore the value of the friction torque of the axial sealing element is $\mathrm{M}_{\mathrm{a}}=11.42 \mathrm{Ncm}$.

In the second step, we calculated the radial friction element (Fig.11). The calculation procedure was similar to that done for the axial friction element. Analogically to the calculation of the axial friction element, the values of the compressive force were achieved. The value of this force in the second 2 of the calculation is $5.1994 \mathrm{~N}$. In case of the radial friction element it is not necessary to calculate the diameter on which the friction element will be positioned as here this value is given structurally and it is $\varnothing 51.85 \mathrm{~mm}$. Then the 
value of the friction torque of the radial friction element is $\mathrm{M}_{\mathrm{r}}=13.48 \mathrm{Ncm}$ and the friction torque of the whole seal is $\mathrm{M}=\mathrm{M}_{\mathrm{a}}+\mathrm{M}_{\mathrm{r}}=11.42+13.48=24.9 \mathrm{Ncm}$.

\section{Experimental verification of numerical results}

This part includes a procedure for detecting the friction torque of the bearing, its components, and the friction elements of the seal on the experimental stand S110 (Fig.14). This experimental stand enables calculating the tested bearing up to the external diameter of $350 \mathrm{~mm}$ and exercising the load of up to $400 \mathrm{~N}$ (radial direction, using an overhang in arrangement). The maximum revolutions of the experimental stand are 10,000 rpm. Fig. 15 depicts the experimental stand S110 with a description of its basic parts.

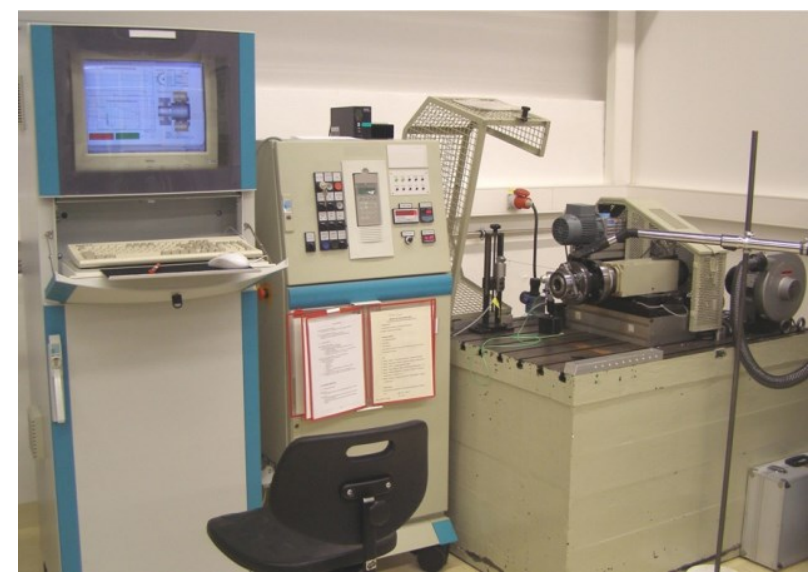

Fig. 14. Experimental stand S110

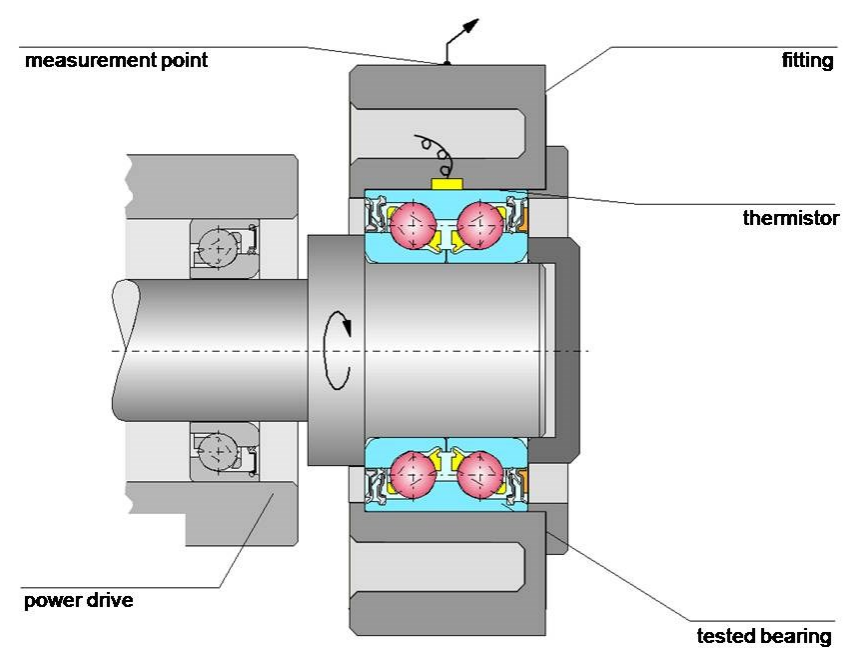

Fig. 15. Scheme of the experimental stand with a description of the basic parts

The calculation principle is based on the fact that the external construction of the bearing is connected to a sensor for measuring the force by way of a wire strand. The internal bearing ring revolves together with a spindle; this movement is in turn transmitted 
to the external ring due to the impact of the friction torque. The magnitude of the force, as measured on the sensor, is then converted using the radius to which the wire strand is attached. The experimental measurement of the friction torque was done on a firstgeneration wheel bearing with the external diameter of $90 \mathrm{~mm}$ and the internal diameter of $56 \mathrm{~mm}$. Four measurements were done for the revolutions of $900 \mathrm{rpm}$; the measurement results are given in Table 1.

Table 1. Results of the friction torques for the tested bearing

\begin{tabular}{|c|c|c|c|}
\hline Measurement & Bearing arrangement & $\begin{array}{c}\text { Friction torque } \\
{[\mathbf{N c m}]}\end{array}$ & $\begin{array}{c}\text { Percentage share } \\
{[\mathbf{\%}]}\end{array}$ \\
\hline $1^{\text {st }}$ & Complete bearing & 98.7 & 100 \\
\hline $2^{\text {nd }}$ & Without one seal & 72.4 & 73.4 \\
\hline $3^{\text {rd }}$ & Without seals & 48.6 & 49.2 \\
\hline $4^{\text {th }}$ & Without lubricant and oil & 45.3 & 45.9 \\
\hline
\end{tabular}

Table shows that the seal on the right side represented $26.6 \%$ of the total friction torque. This corresponds to the value of $26.3 \mathrm{Ncm}$. The seal on the left side represented $24.2 \%$ of the total friction torque of $23.8 \mathrm{Ncm}$. Note that for this experiment we used modified seals that were gradually integrated into the bearing whose friction torque we already know (approximately $45.9 \mathrm{Ncm}$ ). The surfaces of the friction elements that are in contact with the sheetmetal were lubricated with grease. Friction elements were removed from the seals so that one of them only was in contact at a time. The design of the modified seals is shown on Fig.16.
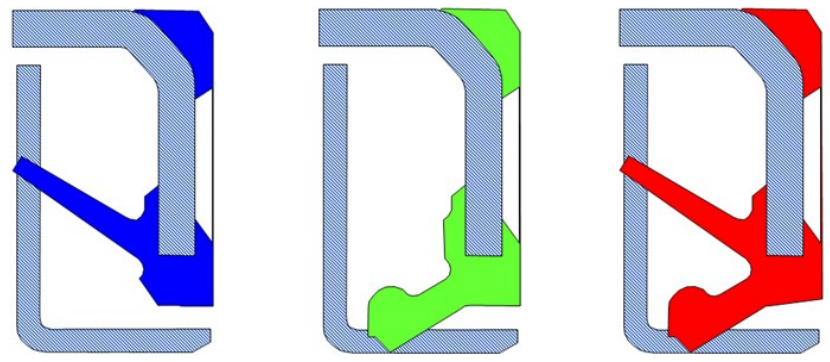

Fig. 16. Updated seals for friction torque measurement

The experiment was done in three steps. Into the bearing we first compressed a seal with a friction element removed in the radial direction, so that the friction torque was produced on the axial friction element only (blue seal; Fig.16). After the measurements were finished, we compressed this seal out of the bearing, instead compressing in a seal with friction elements removed in the axial direction, so that there was friction on the axial friction element (green seal; Fig.16). After the measurements were finished, we finally compressed the seal out, instead compressing in its place a seal with all friction elements (red seal; Fig.16). The evaluation of this experiment is depicted on Fig.17. It shows the influence of the friction elements of the bearing on the friction torque.

The friction torque of the axial friction element (blue seal) was approximately $12 \mathrm{Ncm}$, while the friction torque of the radial element (green seal) reached the value of approximately $14.5 \mathrm{Ncm}$. The value of the friction torque of an unmodified seal (red seal) was approximately $24.5 \mathrm{Ncm}$. However, this value does not have to be necessarily identical to the sum of the measured values of the friction elements because we did not measure the identical seals but rather three modified seals. 


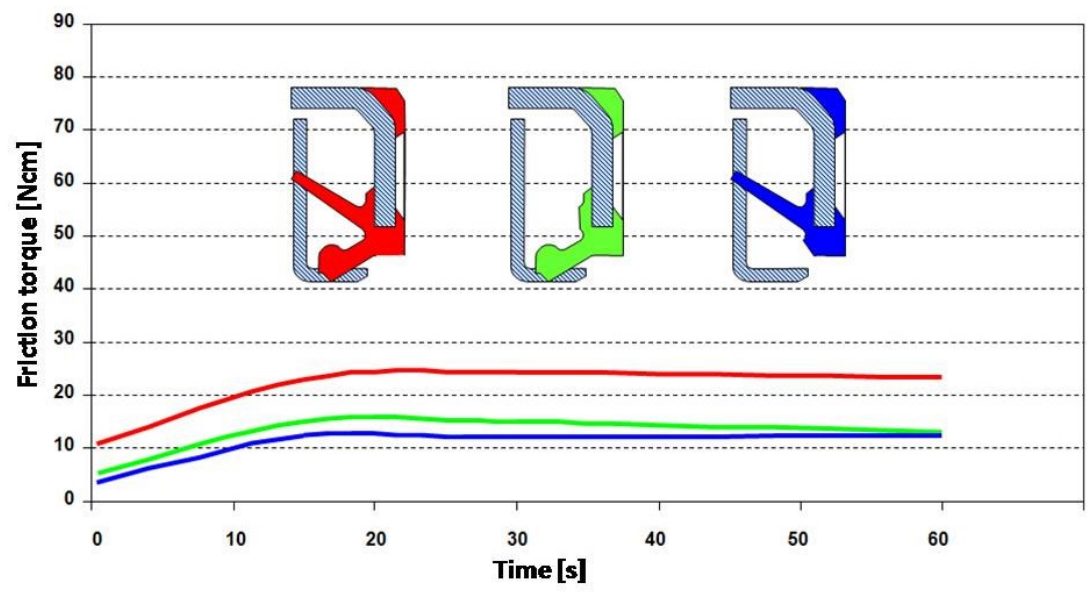

Fig. 17. Course of friction moment of friction lip of the tested seal

Table 2 compares the values of the friction torques achieved in both the experiment and the FEM analysis. The conformity of the results is very good. Deviations may be due to the inaccurate geometry of the used seals, manufacturing inaccuracies, and FEM discretization errors. By comparing the results was verified the accuracy of our calculation and the input data used in the FEM analysis.

Table 2. Results of the experiment and FEM calculation

\begin{tabular}{|c|c|c|}
\hline & $\begin{array}{c}\text { Experiment } \\
{[\mathbf{N c m}]}\end{array}$ & $\begin{array}{c}\text { FEM calculation } \\
{[\mathbf{N c m}]}\end{array}$ \\
\hline Axial lip & 12 & 11.42 \\
\hline Radial lip & 14.5 & 13.48 \\
\hline Axial + Radial lip & 24.5 & 24.9 \\
\hline
\end{tabular}

\section{Sensitivity analysis}

The sensitivity analysis is an important indicator for the designing of machinery components and their material properties, dimensions, etc. It is an analysis of the impact of the input construction parameters on the final characteristics of a model. If we define the input values of the calculation model as $\mathbf{X}=\left(X_{1}, X_{2}, \ldots, X_{M}\right)$ and assume that these are nonzero values, then we can observe the influence of these values on the output value $Y$

$$
Y(\mathbf{X})=f\left(X_{1}, X_{2}, \ldots, X_{M}\right) .
$$

Generally, the sensitivity analysis explores the output indefiniteness of the model caused by various reasons of the indefiniteness of model inputs [7].

This chapter brings a sensitivity analysis of the influence of the deviation of the seal from the nominal dimensions of both the axial and the radial friction elements (Fig. 18). Like the previous analyses, we did an analysis for both the axial and the radial directions. We analysed 60 models created in the Creo 2 program in the environment of the ANSYS WORKBENCH program. The course of the compressive force was assessed because the change in the contact diameter ranges in tenths of a millimetre only, and would have a negligible influence on the calculation itself. Moreover, the calculation would be equally influenced by a round-off error. 


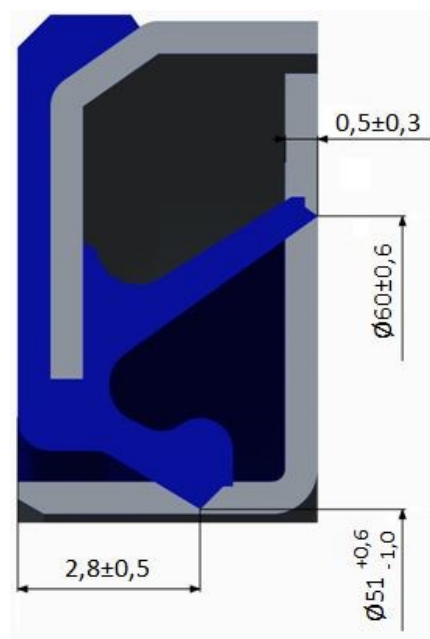

Fig. 18. Geometry of the seal with marked dimensions and tolerances

\subsection{Axial friction torque}

The analysis of an axial friction torque consists of an analysis of an axial friction element in both the axial and the radial directions. Fig. 18 shows the deviations of the geometrical model of the seal: for the axial direction, the deviation is $\pm 0.3 \mathrm{~mm}$, while the growth figure to the nominal value of 0.5 is $0.05 \mathrm{~mm}$; for the radial direction the deviation is $\pm 0.6 \mathrm{~mm}$, while the growth figure is $0.1 \mathrm{~mm}$, corresponding to the nominal value of $\varnothing 60 \mathrm{~mm}$, and the magnitude of the tolerance zone $\pm 0.4 \mathrm{~mm}$. The results of the course of the compressive force are given in the diagrams in Fig. 19 and Fig. 20. Fig.19 shows the course of the compressive force of the axial friction element as well as the values depending on the overhang magnitude with respect to the cover sheetmetal. It is evident that the compressive force increases together with the increasing overhang. Fig. 20 confirms that the compressive force will increase as long as the diameter deviation in the radial direction is negative, and vice versa.

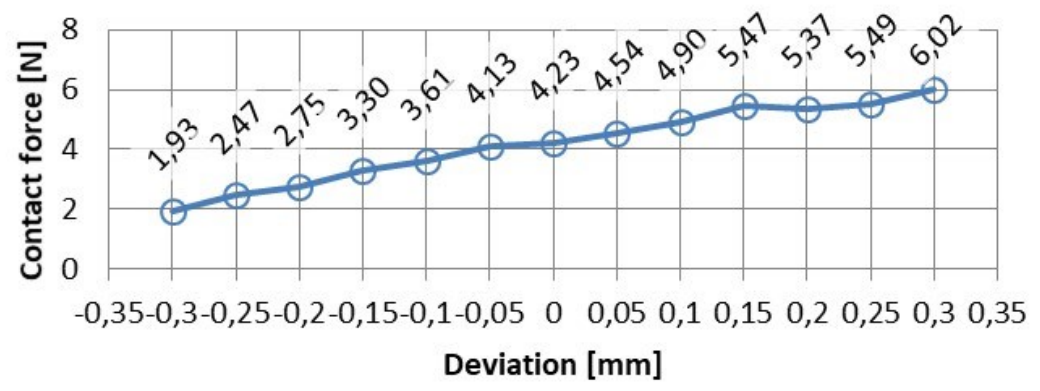

Fig. 19. The course of the axial friction element pressure force when changing its overlap (change of dimension in axial direction) 


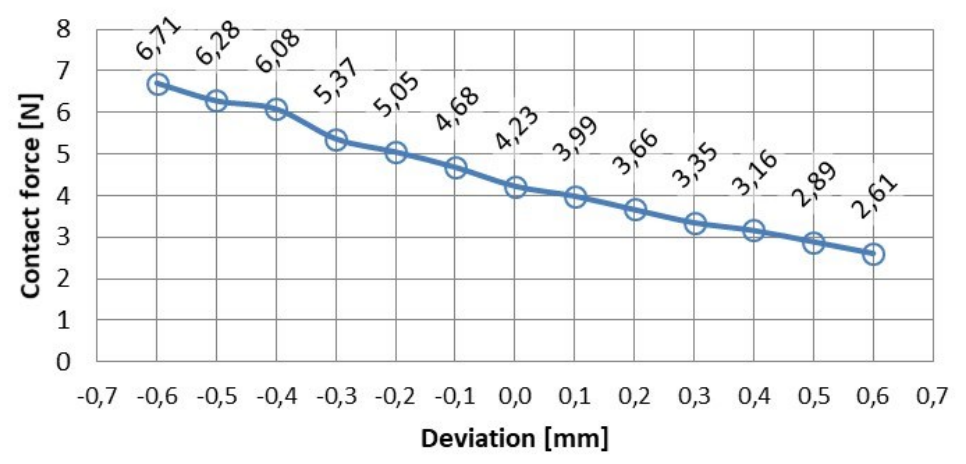

Fig. 20. The course of the axial friction element pressure force when changing its diameter (change of diameter in radial direction)

\subsection{Radial friction torque}

The calculation procedure for the radial friction element is analogical to the axial friction element. The modifications of the geometrical model used in this analysis are given in Fig. 18. For the radial direction ranging from +0.6 to $-1 \mathrm{~mm}$ with the growth figure of $0.1 \mathrm{~mm}$ for the nominal value of $\varnothing 50.9 \mathrm{~mm}$ with the tolerance of $\pm 0.2 \mathrm{~mm}$. The analysis results are given in Fig. 21 and Fig. 22. Fig. 21 depicts the course of the compressive force for the change in the position of the radial friction element in the axial direction. We can see that

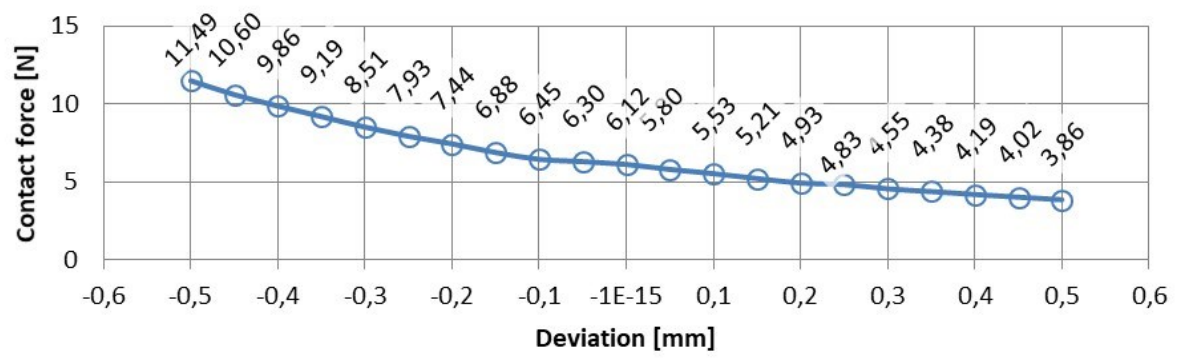

Fig. 21. The course of the radial friction element pressure force when changing its location (change of dimension in axial direction)

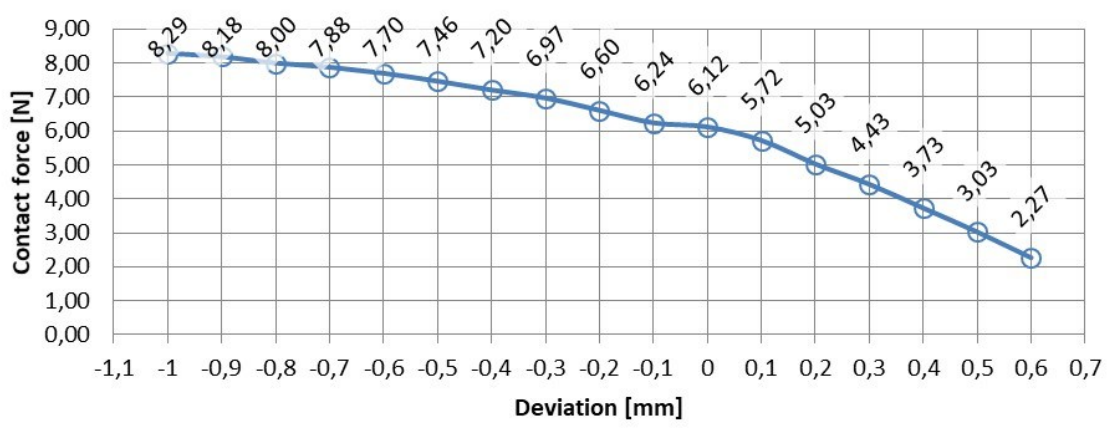

Fig. 22. The course of the radial friction element presure force when changing its overlap (change of dimension in radial direction) 
the compressive force decreases with the increasing deviation. Fig. 22 shows the course of the compressive force, taking into consideration the change of the overhang of the radial friction element with respect to the cover sheetmetal. We can see that the change in the compressive force decreases with the increasing overhang. This is the development opposite to the case of the decreasing overhang when the change in the compressive force increases. The differences in the courses are probably a result of the FEM discretization errors.

\section{Conclusion}

The article brings a procedure for the analysis of sealing systems in the wheel bearing of an automobile. It mainly focused on analysing the friction torques of friction elements when their main dimensions are changed. The ANSYS WORKBECH program was used in the analysis. The geometry was developed in the Creo 2 program. The numerical results clearly show that the method used for the calculation of the friction torque does not require too sophisticated hardware equipment and that the analysis calculation time does not exceed tens of minutes when standard hardware equipment is available. The acquired results give us a good notion of the course of the contact force as well as the friction torque depending on the main dimensions of the friction elements of the sealing system.

In the experimental part, we established the actual values of the friction torques and the compressive forces of the friction elements of the sealing system of the wheel bearing on the experimental stand S110. Having compared the experimental results and the numerical results we can see that the agreement is very good. Minor differences are caused by the tolerance deviations from the drawing values of the sealing geometry as well as the FEM discretization errors.

The research work is partially supported by the Project of the Structural Funds of the EU, Operational Program Research and Development, Measure 2.2 Transfer of knowledge and technology from research and development into practice: Title of the project: Development of optimal technology for the analysis of the limit states of structural elements in contact, ITMS code: 26220220118.

We are support research activities in Slovakia / Project is cofounded from sources of ES.

This work was supported by the Slovak Grant Agency VEGA 1/0983/15.

\section{References}

1. M. Kekez, L. Radziszewski, Modelling of pressure in the injection pipe of a diesel engine by computational intelligence. Proc. of the Institution of Mechanical Engineering, part D-Journal of Automobile Engineering 225, 1660-1670 (2011)

2. W. Tietze, Handbuch Dichtungspraxis. (Vulkan-Verlag Essen, 2003).

3. SKF, Available on internet [http://www.skf.com], (2015)

4. T. Kunstfeld, Einfluss der Wellenoberfläche auf das Dichtverhalten von RadialWellendichtungen. (der Universität Stuttgart, 2005).

5. Y. B. Fu, R. W. Ogden, eds., Nonlinear Elasticity: Theory and Applications (Cambridge University Press, 2001)

6. ANSYS Mechanical User's Guide, ANSYS, Inc., 2015.

7. A. Sapietová, V. Dekýš, Dynamic Analysis of Rotating Machines MSC.ADAMS. Procedia Engineering 136, 143-149 (2016) 